\title{
Age at onset and life table risks in genetic counselling for Huntington's disease
}

\author{
Peter S Harper, Robert G Newcombe
}

\begin{abstract}
Age related genetic risk data for carrying the gene for Huntington's disease in relatives at risk, based on a previously documented life table approach, are presented in a form allowing ready access for use in genetic counselling. Figures are given for first degree relatives and for second degree relatives showing varying age combinations of consultand and intervening parent at risk. Data are also given for the risk of developing Huntington's disease over varying finite periods in relation to age. The availability of this information in tabular form should help those involved in genetic counselling for this disorder in providing accurate risk estimates to relatives; the data are also of importance for combination with genotype information in predictive testing.
\end{abstract}

In genetic counselling for Huntington's disease (HD) risk estimates are critically dependent on the age of the subject at risk. For a person in early adult life with an affected parent, the risk will have declined little from the initial $50 \%$, whereas by the age of 70 the residual risk will be minimal. In between, the risk estimate will depend on the age at onset curve for the disorder.

In 1981 we analysed age at onset data for HD in the south Wales population using a life table method ${ }^{12}$ to correct for underascertainment of those subjects with the gene but not manifesting signs of the disease. We showed that the resulting curve and risk estimates differed considerably from those based on uncorrected age at onset data. Since that time a life table approach has been used on other HD populations with comparable results. ${ }^{3}$ Age at onset studies based on remote data have also shown a later onset curve ${ }^{4}$ and where it has been possible to use the different methods together the life table and remote data estimates have agreed closely. ${ }^{3}$

The life table approach has subsequently been used for other dominantly inherited disorders of variable age at onset, such as myotonic dystrophy. ${ }^{5}$ It is generally agreed that for genetic counselling it provides risk estimates that are more accurate than those based on a crude age at onset curve.

We have used age related risk estimates for genetic counselling in HD, based on life table calculations, for a considerable time ${ }^{6}$ as have others. ${ }^{7}$ However, no convenient and comprehensive tabulation of such risks has hitherto been available, particularly for second degree relatives. Recently these risks have assumed added importance in relation to presymptomatic tests for the $\mathrm{HD}$ gene using DNA markers, where the age related risk must be combined with the genotype data for the most accurate risk assessment. During the course of an extensive presymptomatic detection programme, ${ }^{89}$ with numerous referrals from other centres, it has become apparent that not all those involved in genetic counselling for HD were using risk estimates based on the life table approach.

We present here a detailed breakdown of age related risks for first and second degree relatives, given in both tabular and graphic form. We hope that this will allow easier application of life table generated risks than has hitherto been possible, especially for those centres whose family data on HD are insufficient to generate their own age at onset curves.

\section{Methods}

The data presented are based on the original south Wales study of HD that formed the basis of our earlier age at onset analysis. ${ }^{1011}$ While these data have been updated subsequently, the original study has the advantage that the data were collected personally by a single clinical worker. The method used to generate the risk estimates is that of Newcombe, ${ }^{1}$ with additional calculations to give the risks for second degree relatives.

\section{Results}

Table 1 and fig 1 give the age related risk estimates for first degree relatives with a parent affected by HD. In the table the mid point

Table 1 Risk for a healthy subject at $50 \%$ prior risk of $H D$ carrying the HD gene at different ages. Based on the life table analysis of south Wales data.

\begin{tabular}{cc}
\hline Age $(\mathrm{y})$ & Risk $(\%)$ \\
\hline $20 \cdot 0$ & $49 \cdot 6$ \\
$22 \cdot 5$ & $49 \cdot 3$ \\
$25 \cdot 0$ & $49 \cdot 0$ \\
$27 \cdot 5$ & $48 \cdot 4$ \\
$30 \cdot 0$ & $47 \cdot 6$ \\
$32 \cdot 5$ & $46 \cdot 6$ \\
$35 \cdot 0$ & $45 \cdot 5$ \\
$37 \cdot 5$ & $44 \cdot 2$ \\
$40 \cdot 0$ & $42 \cdot 5$ \\
$42 \cdot 5$ & $40 \cdot 3$ \\
$45 \cdot 0$ & $37 \cdot 8$ \\
$47 \cdot 5$ & $34 \cdot 8$ \\
$50 \cdot 0$ & 31.5 \\
$52 \cdot 5$ & $27 \cdot 8$ \\
$55 \cdot 0$ & $24 \cdot 8$ \\
$57 \cdot 5$ & $22 \cdot 1$ \\
$60 \cdot 0$ & $18 \cdot 7$ \\
$62 \cdot 5$ & $15 \cdot 2$ \\
$65 \cdot 0$ & $12 \cdot 8$ \\
$67 \cdot 5$ & $10 \cdot 8$ \\
$70 \cdot 0$ & $6 \cdot 2$ \\
$72 \cdot 5$ & $4 \cdot 6$
\end{tabular}


$\%$

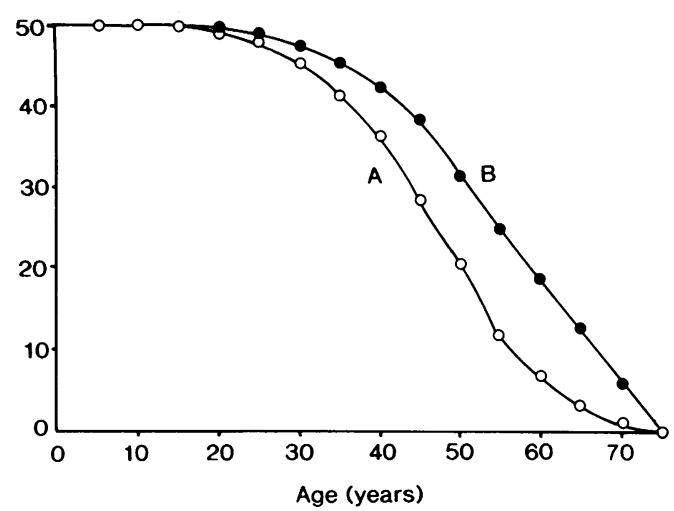

Figure 1 Risk of an unaffected subject at $50 \%$ prior risk for $H D$ carrying the $H D$ gene at a particular age. Curve $A$ is based on the uncorrected age at onset curve, curve $B$ on the life table analysis, corresponding to the data given in table 1.

estimate for the five year age groups has been used for the calculations; the curve is derived from these estimates but allows a more specific risk figure to be given for intervening ages, which are also given in table 1 . It should be noted that the risk estimate is for possessing the HD gene, not for developing the disorder.

In fig 1 the curves for heterozygosity based on uncorrected age at onset data (fig 1A) and on the life table estimate (fig 1B) are compared. It can be seen that the life table derived curve produces a considerably higher risk estimate at any given age, particularly in the older age groups.

In tabie 2 the risks are given for second degree relatives (usually subjects with an affected grandparent). The cross tabulation allows an estimate to be made for any combination of ages of the second degree relative and the intervening parent at risk. The latter can be his/her current age, if still alive and unaffected, or age at death without manifesting the disorder. Fig 2 gives corresponding curves for four different parental ages.

Fig 3 illustrates three examples of the use of table 2, all of which are situations frequently encountered in genetic counselling.

In fig $3 \mathrm{~A}$, the subject requesting counselling is young, so that most of the risk modification results from the age of the unaffected parent; the estimate is not greatly different from that obtained by halving the parental estimate obtained from table 1 or fig 1 .
In fig 3B both the second degree relative and the intervening parent are considerably older, with a resulting low risk estimate. It can be seen from inspection of table 2 that all risk estimates in this upper right section of the table are low, in some cases effectively negligible.

Fig $3 \mathrm{C}$ gives an example of an important and relatively frequent situation, where the intervening parent has died from an unrelated cause. Information from this parent bearing on the issue of the genotype of the second degree relatives is thus effectively 'frozen' at this point. Table 2 should be particularly helpful in allowing the most accurate estimates in this type of situation.

A final area of risk estimation in genetic counselling is for the risk of developing the disorder over a defined period. Table 3 shows this for first degree relatives over varying time periods and age ranges. It can be seen that some of these risk estimates, especially for younger age groups, are extremely low in relation to the overall lifetime risk, and that the risk estimate depends almost as much on the age group as on the length of the period involved.

\section{Discussion}

None of the data presented above are strictly original, all being derived from the south Wales study and life table analysis already published. However, risk data have not, to our knowledge, been presented in this way for second degree relatives, nor have general estimates for finite risk periods been presented previously.

Although our data are derived from a specific HD population, that of south Wales, it seems unlikely that there are major differences from other large populations elsewhere, though for isolated populations derived from one or a few ancestors the pattern could be different. It should be noted that there are several variables involving age at onset that have not been taken into account, partly because of the additional complexity that would be introduced, but more importantly because they are at present difficult to estimate quantitatively. These include the following.

(1) Effect of the sex of transmitting parent. It is well established that juvenile HD (onset under 20 years) is predominantly paternally transmitted ${ }^{12}$; most, but not all, studies have shown an overall earlier onset of paternally

Table 2 Risk estimates (\%) for second degree relatives of a patient with $H D$.

\begin{tabular}{|c|c|c|c|c|c|c|c|c|c|c|c|c|}
\hline \multirow[t]{2}{*}{$\begin{array}{l}\text { Age of } \\
\text { child } \\
\text { (years) }\end{array}$} & $\begin{array}{l}70- \\
65- \\
60- \\
55- \\
50- \\
45- \\
40- \\
35- \\
30- \\
25- \\
20-\end{array}$ & $\begin{array}{r}1.6 \\
3.8 \\
5.6 \\
8.5 \\
11.2 \\
14.9 \\
18 \cdot 1 \\
20.6 \\
22.2 \\
23.5 \\
24.2\end{array}$ & $\begin{array}{r}1.5 \\
3.7 \\
5.4 \\
8.3 \\
10.9 \\
14.6 \\
17.8 \\
20.2 \\
21.8 \\
23.1 \\
23.7\end{array}$ & $\begin{array}{r}1.5 \\
3.5 \\
5.2 \\
7.9 \\
10.5 \\
14.0 \\
17.0 \\
19.4 \\
20.9 \\
22.2 \\
22.8\end{array}$ & $\begin{array}{r}1 \cdot 4 \\
3.3 \\
4.9 \\
7 \cdot 4 \\
9 \cdot 8 \\
13 \cdot 2 \\
16 \cdot 1 \\
18 \cdot 4 \\
19.9 \\
21 \cdot 0 \\
21.7\end{array}$ & $\begin{array}{r}1.2 \\
3.0 \\
4.3 \\
6.7 \\
8.9 \\
11.9 \\
14.6 \\
16.7 \\
18.1 \\
19.2 \\
19.7\end{array}$ & $\begin{array}{r}1.0 \\
2.5 \\
3.7 \\
5.6 \\
7.5 \\
10.1 \\
12.5 \\
14.3 \\
15.5 \\
16.5 \\
17.0\end{array}$ & $\begin{array}{r}0.8 \\
1.9 \\
2.8 \\
4.4 \\
5.8 \\
7.9 \\
9.8 \\
11.3 \\
12.3 \\
13.1 \\
13.6\end{array}$ & $\begin{array}{r}0.6 \\
1.5 \\
2.2 \\
3.4 \\
4.6 \\
6.2 \\
7.7 \\
9.0 \\
9.8 \\
10.4 \\
10.8\end{array}$ & $\begin{array}{l}0.4 \\
1.0 \\
1.5 \\
2.3 \\
3.1 \\
4.2 \\
5.3 \\
6.1 \\
6.7 \\
7.2 \\
7.4\end{array}$ & $\begin{array}{l}0.3 \\
0.7 \\
1.0 \\
1.6 \\
2 \cdot 1 \\
2 \cdot 9 \\
3.7 \\
4 \cdot 3 \\
4 \cdot 7 \\
5 \cdot 1 \\
5 \cdot 2\end{array}$ & $\begin{array}{l}0.1 \\
0.3 \\
0.4 \\
0.7 \\
0.9 \\
1.3 \\
1.6 \\
1.8 \\
2.0 \\
2.2 \\
2.3\end{array}$ \\
\hline & & $20-$ & $25-$ & $30-$ & $35-$ & $\stackrel{40-}{\text { Age }}$ & $\begin{array}{l}45- \\
\text { parent }\end{array}$ & $\begin{array}{c}50- \\
\text { ars) }\end{array}$ & $55-$ & $60-$ & $65-$ & 70 \\
\hline
\end{tabular}

The table shows the residual risk of a healthy second degree relative carrying the HD gene at various combinations of age for the child and the intervening parent. Data from the south Wales life table analysis. ${ }^{1}$ 


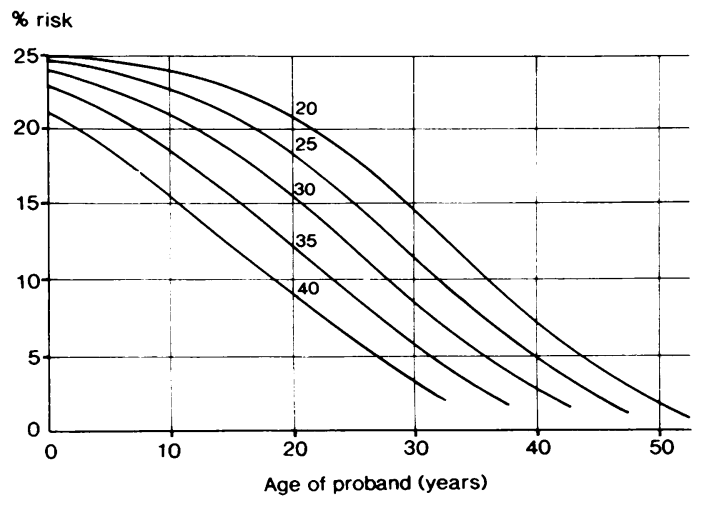

Figure 2 Risk curves for second degree relatives. This series of curves shows the decline in risk of carrying the $H D$ gene with age for a proband who is the grandchild of a patient with $H D$, and who has an unaffected living parent. The different curves correspond to the age of the intervening parent at risk at the time the proband was born. Table 2 gives the risk figures in more detail.

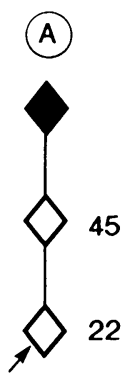

Risk (\%) 17.0

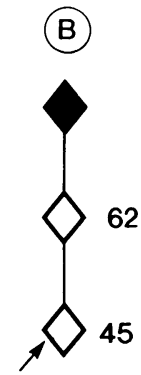

4.2

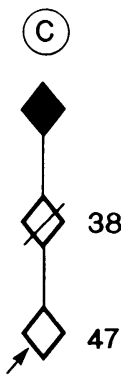

13.2

Figure 3 Risk estimates for second degree relatives in different genetic counselling situations. ( $A$ ) Second degree relative and parents both relatively young. $(B)$ Second degree relative and parents both relatively old. (C) Intervening parent at risk dead from an unrelated cause (see text for details).

transmitted cases. ${ }^{1314}$ Until there is more general agreement on the magnitude of this difference over the entire age range it seems unwise to incorporate such sex differences into the general analysis. Hayden et $a l^{15}$ have provided a risk curve for sibs of juvenile cases based on the US Huntington's roster; this is probably more appropriate for this special group than the overall data given here, though it should be noted that the curve of Hayden et $a l^{15}$ is based on uncorrected age at onset. A recent study of sibships where a member has shown onset under 10 years of age suggests

Table 3 Risk (\%) of onset of HD over a defined period in a person at $50 \%$ prior risk calculated from the original south Wales life table analysis.'

\begin{tabular}{|c|c|c|c|c|c|c|}
\hline \multirow[t]{2}{*}{ Age of person } & $\begin{array}{l}50- \\
45- \\
40- \\
35- \\
30- \\
25- \\
20-\end{array}$ & $\begin{array}{l}7 \cdot 3 \\
9 \cdot 8 \\
8 \cdot 5 \\
6 \cdot 5 \\
4 \cdot 2 \\
3 \cdot 4 \\
1 \cdot 8\end{array}$ & $\begin{array}{r}14.8 \\
16.4 \\
17.4 \\
14.4 \\
10.5 \\
7.5 \\
5.1\end{array}$ & $\begin{array}{r}19 \cdot 1 \\
23 \cdot 1 \\
23.5 \\
22 \cdot 8 \\
18 \cdot 0 \\
13.5 \\
9 \cdot 1\end{array}$ & $\begin{array}{l}24 \cdot 3 \\
27 \cdot 0 \\
29 \cdot 6 \\
28 \cdot 4 \\
26 \cdot 1 \\
20 \cdot 8 \\
15 \cdot 1\end{array}$ & $\begin{array}{l}24 \cdot 3 \\
31 \cdot 7 \\
33 \cdot 2 \\
34 \cdot 2 \\
31 \cdot 5 \\
28 \cdot 6 \\
22 \cdot 2\end{array}$ \\
\hline & & 5 & $\begin{array}{c}10 \\
\text { Time } p\end{array}$ & $\begin{array}{l}15 \\
\text { from }\end{array}$ & $\begin{array}{c}20 \\
\text { t (yea }\end{array}$ & 25 \\
\hline
\end{tabular}

close concordance for age at onset in these rare instances. ${ }^{16}$

(2) No allowance has been made for familial correlation of age at onset, though such a correlation is well documented. ${ }^{213}$ Because the range of variation is so great even within a single kindred it is rarely feasible to utilise intrafamilial correlation unless one is dealing with an exceptionally large and well documented kindred. Most families seen for counselling do not have an adequate number of affected members to permit this.

(3) Our estimates of age at onset have been based on definite clinical onset of either neurological or psychiatric symptoms. Because HD generally develops very gradually, often with a period of years when suspicious but not diagnostic features are present if a person is being seen regularly, it is likely that our risk estimates may be excessive for a subject who is totally normal on detailed assessment. A recent report based on longitudinal study of the Venezuela HD isolate ${ }^{17}$ has suggested that a subject who is totally normal on the quantitative neurological examination has only a 3\% chance of developing clinically definite HD over the subsequent three years.

None of these variable factors invalidate the general risk tables given in this paper, but they should be borne in mind by those giving genetic counselling; where appropriate they may allow an adjustment of the risk estimate.

The estimates of risk over finite time periods given here should be of considerable value in genetic counselling, since many subjects at risk are especially concerned about the immediate future as well as their overall lifetime risk. These estimates are also relevant to major decisions that persons may be considering in terms of career, while they could also be of value in relation to insurance. Agencies involved in adoption and fostering should also be aware of these risks; for example, placing of an older child with a young couple whose risk over the following five to 10 years is low might be considered acceptable by comparison with the overall lifetime risk of $50 \%$ that is generally used.

The increasing use of predictive testing based on closely linked DNA markers is now allowing a more accurate prediction than is possible from age adjusted risks above. However, it is essential that in estimating risks based on such tests, accurate age related risks are incorporated, not only for the person requesting testing, but also on unaffected older relatives being utilised as 'escapees'. Ignoring such risks, or using risks based on uncorrected age at onset, may result in serious error, sometimes giving a spurious impression of definitiveness to the predictive test result; the considerable residual risk for $\mathrm{HD}$ of subjects in their 50 s or early 60 s means that it is unwise to use such people as 'unaffecteds'.

Isolation of the HD gene and the detection of specific mutations should, in time, further remove many of the remaining uncertainties of risk estimation in HD. However, many subjects are likely not to wish for such testing, 
while for all subjects seen for genetic counselling, age related risk estimation should be as accurate as possible. We hope that the estimates given here in simple form will help to ensure that all HD families are able to be given accurate and specific risk estimates to help them in making major life decisions and in coming to terms with their own particular situation.

1 Newcombe RG. A life table for onset of Huntington's chorea. Ann Hum Genet 1981;45:375-83.

2 Newcombe RG, Walker DA, Harper PS. Factors influencing age at onset and duration of survival in Huntington's chorea. Ann Hum Genet 1981;45:387-96.

3 Adams P, Falek A, Arnold J. Huntington disease in Georgia: age at onset. Am f Hum Genet 1988;43:695-704.

4 Wendt GG, Drohm D. Die Huntingtonsche Chorea. Eine populationsgenetische Studie. Stuttgart: Thieme, 1972.

5 O'Brien T, Newcombe RG, Harper PS. Outlook for a clinically normal child in a sibship with congenital myotonic dystrophy. $\mathcal{F}$ Pediatr 1983;103:762-3.

nic dystrophy. 7 Pediatr 1983;103:762-3.
6 Harper PS. Practical genetic counselling. 3rd ed. London: Wright, 1988 .

7 Baraitser M. Genetics of neurological disorders. Oxford: Oxford University Press, 1990.
8 Morris MJ, Tyler A, Lazarou L, Meredith L, Harper PS. Problems in genetic prediction for Huntington's disease. Problems in genetic
Lancet 1989;ii: $601-3$.

9 Harper PS, Morris M. Predictive testing for Huntington's disease. In: Harper PS, ed. Huntington's disease. London:

10 Walker DA, Harper PS, Wells CGC, Tyler A, Davies K, Newcombe RG. Huntington's chorea in South Wales. A genetic and epidemiological study. Clin Genet 1981; 19:213-21.

11 Walker DA, Harper PS, Newcombe RG, Davies K. Huntington's chorea in south Wales. Mutation, fertility, and genetic fitness. I Med Genet 1983;20:12-17.

12 Merrit AD, Conneally PM, Rahman NF, Drew AL. Juvenile Huntington's chorea. In: Barbeau A, Brunette JR, eds. Progress in neurogenetics. Amsterdam: Excerpta Medica, 1969.

13 Conneally PM. Huntington's disease: genetics and epidemiology. Am f Hum Genet 1984;36:506-26.

14 Went LN, Vegter-van der Vlis M, Bruyn GW, Volkers WS Huntington's chorea in the Netherlands. Ann Hum Genet 1983;47:205-14.

15 Hayden MR, Soles JA, Ward RH. Age of onset in siblings of person with juvenile Huntington disease. Clin Genet 1985;28:100-5.

16 Clarke DJ, Bundey S. Very early onset Huntington's disease: genetic mechanism and risk to siblings. Clin Genet ease: genetic me

17 Penney JB, Young AB, Shoulson I. Huntington's disease in Venezuela: 7 years of follow-up on symptomatic and asymptomatic individuals. Movement Dis 1990;5:93-9. 